\title{
THE POST-SECONDARY NETWORKED CLASSROOM: RENEWAL OF TEACHING PRACTICES AND SOCIAL INTERACTION
}

\section{Milton Campos}

Assistant Professor

Département de communication

Faculté des arts et des sciences

Université de Montréal

C.P. 6128, succursale Centre-ville

Montréal - QC - H3C 3J7, Canada

Tel - (514) 343-2066

Fax - (514) 343-2298

E-mail - Milton.Campos@umontreal.ca

http://www.fas.umontreal.ca/COM/Interactiva/Index.htm

\section{Thérèse Laferrière}

Professor

Département d'études sur l'enseignement et l'apprentissage

Faculté des sciences de l'éducation

Université Laval, Ste-Foy

Québec - QC - G1K 7P4, Canada

Tel - (418) 656-2131 ext. 5480

Fax - (418) 656-7347

E-mail - tlaf@fse.ulaval.ca

http://www.tact.fse.ulaval.ca

\section{Linda Harasim}

Professor

School of communications

Simon Fraser University

8888 University Drive

Burnaby - BC - V5A 1S6, Canada

Tel - (604) 291-5296

Fax - (604) 291-3987

E-mail - harasim@sfu.ca

http://www.telelearn.ca/g_access/harasim.html

\begin{abstract}
The application and use of telelearning technologies in post-secondary education is evolving from peripheral activities to central approaches. Educators are re-discovering collaborative education as they understand how electronic conferencing can support and empower teaching and learning. As students build knowledge collaboratively, asynchronous conferencing elevates engagement and participation, and increases thinking and understanding. This article presents the teaching practices of post-secondary educators who integrated asynchronous electronic conferencing in over one hundred mixed-mode courses at eight North American institutions between 1996 and 1999. Quantitative and qualitative research methods were applied to assess their practices and to further understand the correlation between the use of electronic conferencing and the
\end{abstract}


degree of collaboration achieved. Based on the findings, pedagogical approaches for the use of electronic conferencing are provided, and are grouped according to the level of collaboration. As a result of this study, the authors present a suggested model for the networked classroom to foster and guide the transformation of pedagogical practice.

\section{KEYWORDS}

Networked classroom, collaborative learning, communicative interaction, higher education, online learning, pedagogy

\section{INTRODUCTION}

Traditionally, telelearning has been associated with distance education, wherein instruction is provided to students who are unable to attend campus-based courses. While initially delivered by mail, distance education courses were later enhanced with multimedia. In addition to exercise books mailed to students, lessons supplemented by radio and television added dynamism and helped students to have a sense of "presence" from a distance. With today's popularization and use of online media and the Internet ${ }^{1}$ distance education is rapidly changing.

Today, post-secondary campus-based education delivery is also taking advantage of and adopting learning networks. Learning networks were defined by Harasim et al. as "groups of people who use CMC [computermediated-communication] networks to learn together, at the time, place, or pace that best suit them and is appropriate to the task" $[\mathrm{p} .4 ; 14]$. Network-enhanced learning is therefore applied as a collaborative learning activity for knowledge building purposes [4] [10]. Networked classrooms are, thus, classrooms with extended capabilities, wherein asynchronous electronic conferencing is used to build shared collaborative spaces as a means to achieve set learning goals. We argue that because the mixed-mode delivery is likely to become mainstream in post-secondary North American institutions, it is worth looking at the way it is being implemented in order to better understand its nature and contribution to teaching and learning. The mixedmode is a combination of online and regular instructional strategies "in which a significant portion of a faceto-face or distance education class is conducted by e-mail or computer conferencing" $[\mathrm{pp} .77 ; 14]$.

Many challenges emerge from this new educational context, carrying with them questions that need to be answered to advance our knowledge of networked learning processes in post-secondary institutions [19]. How are campus-based educators integrating online collaborative activities into their teaching practices? Is this emerging trend shifting towards traditional distance education practices, or towards a renewed, collaborative relationship between educators and students? This article identifies the components of networked classrooms, clusters of pedagogical activities, and levels of collaboration and how these levels shape specific types of networked classrooms. The authors present the theoretical framework applied, the method of inquiry and analysis used, and the results achieved. Finally, we argue that in order to design an exemplary model for the networked classroom, socio-cognitive factors are intrinsic to applying and understanding this new pedagogical phenomenon.

\section{THEORETICAL FRAMEWORK}

The socio-constructivist perspective focuses primarily on human action and interaction in order to understand pedagogical practices in the networked classroom. We denote action as the socio-biological dynamic (structural and functional; phylogenetic and genetic) that is triggered by the physical and symbolic exchange between subjects, or between subjects and symbolic objects (such as computers, television, radio, etc.). Biological functions, neural structures subjacent to all intelligent behavior, including learning [20] 
[21], and configurations of meanings [10] [11] work together as engines of action that is the intentional process of the knowing subject. Piaget pointed to the importance of action for the development of the knowing subject [21] [22] [23].

In addition to the structural-biological dimension of the knower, another assumption is that action cannot be understood without taking into account the social-cultural environment in which it occurs, and that recursively shapes its own structure. Action implies phylogenetic processes that express culture at its highest level [27]. Educational settings are exemplary for the purpose of understanding how society and its cultural components shape those processes [2]. Moreover, educational settings propitiate the emergence of communities built around consensual social learning practices [28], be those communities traditional (faceto-face) or ones that integrate new technologies such as asynchronous conferencing [3]. Our approach of socio-cognition goes beyond the idea that knowledge acquisition is mere treatment of information as representational symbols functioning from a set of innate rules applied for problem solving (information processing theory) or that it is the emergence of global states in a network of simple components in which local innate rules shape a system able to solve a problem (connexionism) [26]. Rather, cognition is productive action able to promote structural changes in a system, creating history either by aggregating a pre-existent world of meanings in continual development or by creating a new one as a result of that history (enacting theory) [26] [20].

Cole \& Engeström [13] proposed a model applicable to the study of interactions through computer networks inspired by the cultural historical tradition [27] that focuses on activity rather than centering pedagogy on action. By taking activity (an aspect of action) as the focusing point, this model provided the authors with a guiding theoretical framework for research data analysis at the activity level. Cole's and Engeström's theoretical model suggests a dynamic categorization of a number of dimensions to be found in activity: a subject, an object, a community, a mediating artifact, rules, and division of labor. However, although these dimensions are useful as an instrumental means to analyze pedagogical processes, they are not presented in the model as an integrated whole. Understanding action holistically implies the consideration of logic (procedures subjacent to meanings) with content (meanings that involves procedures, or taken in more general terms, culture) in the living dynamics of behavior, depending on the variability of human psychogenetic traits. Our working hypothesis is that teachers' actions in mixed-mode networked courses are units suitable for analysis to better understand the dynamics of early teaching practices occurring in the emerging networked classroom.

For pedagogical action we group the following actions taken by educators in mixed-mode networked classrooms: providing orientation of the educational scenario, establishing the learning goals, structuring activities around tasks, organizing the learning environment, defining roles the actors should play, and the rules of participation. In this study, we pay particular attention to the pedagogical action that aims at building collaborative classrooms through the implementation of networked technologies.

\section{METHOD}

The authors studied mixed-mode courses taught by educators between 1996 and 1999 in eight postsecondary institutions: six in Canada and two in the United States. The Canadian participating institutions were distributed across the country: three were English and French speaking universities, and the fourth one was a post-secondary community college. The two American institutions were a Mid-Western and an Eastern university. All post-secondary institutions took or are still taking part of the field site trials of the Virtual-U Research Project (http://virtual-u.cs.sfu.ca/vuweb/VUEnglish/). 
We studied 132 mixed-mode courses taught from 1996 to 1999: 65\% undergraduate, 24\% graduate, and $11 \%$ at the collegial level. Instructors used Virtual-U, a web-based virtual learning environment specifically designed to support knowledge building and collaborative learning [12] [16], which contains a reliable state-of-the-art built-in conferencing system. This conferencing system (VGroups) was developed to enable participants to broaden their "thinking worlds" through online dialogue both during and between face-toface meetings. ${ }^{2}$

Thirty-eight instructors taught those courses. Most of them were inexperienced: $16(42 \%)$ had just taught one online mixed-mode course; 11 instructors (29\%) had taught 2 courses; 6 (16\%) had taught 3 courses; and the remaining $5(13 \%)$ had taught more than 4 courses.

We prepared and carried out extensive surveys to collect course data from numerous disciplines taught by the educators. Disciplines were distributed as follows: Business (19\%), Law (2\%), Social Sciences (8\%), Applied Sciences (6\%), Health Sciences (3\%), Arts \& Humanities (17\%), Education (39\%), and Other (6 $\%)$.

Different types of data were collected in order to meet the following specific objectives:

- course syllabi to understand how the courses were conceptualized, structured, and organized;

- in-depth interviews with the educators to assess their experiences: why they decided to teach online, how they were adjusting to the networked environment and adapting their teaching to it, what changes they made from traditional face-to-face courses, how they evaluated their own teaching processes, and to what extent collaboration was intentionally integrated into their teaching strategies;

- demographics and general information about the online experiences of the educators; and

- analysis of online interaction through conference transcripts. ${ }^{3}$

The authors applied the qualitative technique of data reduction. Complementary data were used, and repetitive or inconsistent data were eliminated. The authors sought identifiable patterns in the educators' pedagogical actions in relation to the use of conferencing in order to determine similarities in teaching practices. The results are presented below.

\section{RESULTS}

\section{A. Components of networked classrooms}

\section{Goals, activities and tasks}

In this category, the authors examined teaching and learning goals, the activities designed to help ensure goal achievement, and the tasks through which activities surrounding the use of conferencing were structured. Primarily, the authors determined that the course goals varied and were context dependent. In relation to activities and tasks, the authors identified a pattern whereby all courses included at least one or many of the following online activities, and related specific tasks:

- to develop a theme of common interest

- to explore a specific topic

- to answer a question

- to solve a problem through discussion

- to prepare and to work on a project 
- to work on a text (either a text given by an educator or a text created by the participants)

\section{Organization}

By organization the authors imply the way in which educators set up online conferences, attribute learning objectives to the conferences, and define tasks through which students were to achieve the goals. In the majority of the courses analyzed, the conferences appear to stem from the core of the teaching and learning processes. While educators had other online tools ${ }^{4}$ at their disposal for structuring activities, they used asynchronous conferencing for this very purpose as well ${ }^{5}$.

The educators organized either general or specific conferences. The general conference was created for courses where only a single or root conference was used by participants, and in which specific online activities were not related to specific learning tasks. All activities occurred in the same single or root conference throughout the course, and were independent of the different topics being discussed. Where specific conferences were organized, more than one sub-conference was created from the root conference, and discussions took place around specific activities and tasks. In this case, a specific activity or task was usually attached to a specific sub-conference. Typically, many sub-conferences were created, each one used for a specific activity or task. In some instances, educators set up sub-conferences for the exclusive use of groups independently carrying out the same activity or task.

\section{Roles}

We term role as the function that a) educators used to guide students, and b) students adopted to carry out activities and tasks organized in or through the conferences.

We identified two main roles that the educators played in the conferences: that of facilitator, and that of publisher. In both cases all educators engaged in, at least a minimal level of knowledge sharing or other collaborative activity. The role of facilitator is viewed here as intrinsically collaborative in that pedagogical action is taken with the support of the conferencing system. Facilitators engage students to discuss and share contributions, and to guide collective shaping as online conversations deepen. The role of publisher is viewed as extrinsically collaborative wherein pedagogical action is focused on sharing of produced materials rather than ideas in elaboration. In cases where educators used the conferences for publishing, the material was posted to be shared. It was, nonetheless, collaborative but to a lesser degree than facilitation.

\section{a. Facilitation}

We identified a continuum and escalation of facilitation methods: observation, moderation, and negotiation. Few educators limited themselves to purely observing what was taking place in the conferences. Educators followed the conference activities and tasks developed by students without direct intervention. Action was only taken by educators when they observed that discussions were inappropriate to the learning direction. Most educators chose to moderate. They typically guided the ongoing student learning processes reflecting on student discussions, sharing summaries of contributions, and understanding the discussions for continued debate.

Moreover, some educators engaged in the negotiation of meanings and of role definition. They went beyond moderating the learning process by taking a more participative role through engaging at the substantive level and becoming, along with their students, knowledge builders. They collaborated with students to provide the conceptual means to fine-tune discussions, helping them to shape an environment in which higher-order argumentation could take place (collaborative knowledge building). ${ }^{6}$ 


\section{b. Publishing}

The publishers acted as lecturers of regular classrooms. Educators used the virtual learning environment strictly to publish lessons related to the courses, to provide links to resources, and to share materials. Knowledge was not necessarily shared through online discussion, and where conferencing was used, it was to a lesser extent. Analysis of the data showed that this online "lecturing" role encouraged instructor-student interaction rather than student-student interaction.

\section{Rules of participation}

The authors term rules of participation as the normative standards established for participation in order to make clear what activities had to be carried out, how they had to be organized, through which tasks, when, why, by whom, and where participants were expected to act.

The authors observed that educators were critical to structuring conferencing activities. Some rules of participation were specifically defined, wherein interaction was controlled, while others were unrestricted wherein educators allowed students to create and/or propose their own rules of participation.

\section{B. The pedagogical-action clusters}

When addressing the relationships between components of the pedagogical action (goals, activities and tasks, organization, educators' and students' roles, and rules of participation) the authors determined some patterns related to:

- collaborative and individual work (more collaborative than individually - balanced, and more individual than collaborative);

- face-to-face and online activities/ tasks (more face-to-face than online, and more online than face-to-face)

- educators' online experience (seasoned, experienced, or new).

We term pedagogical-action clusters as groupings of similar mixed-mode collaborative teaching practices shaped by the patterns presented above, in which the goals, activities, and tasks drove the organization of the conferences, educators' roles, and rules of participation. From the multiplicity of possible combinations, the authors identified the following pedagogical action clusters from the data collected: (1) stand-alone specific activities, (2) collaborative learning projects, (3) simulation activities, (4) theme development, text structuring, and case studies, (5) network-enhanced lecture, (6) networked-enhanced seminar, and (7) networked-enhanced teaching practicum.

\section{Stand-alone specific activities}

Stand-alone specific activities are defined as conferencing used for specific networked activities such as online reading and knowledge sharing, group production of virtual objects, Internet search, collective multimedia projects, etc. Most activities and tasks inferred the use of technology. Face-to-face and/or online as well as individual and collaborative activities were well balanced. In this cluster, all educators were experienced, having taught at least two online courses.

\section{Collaborative learning projects}

This cluster groups courses based on collective or group projects using multimedia software. Activities and tasks evolved in and through online discussions (e.g., the planning and implementation of the projects). Face-to-face and online activities were well balanced. Online individual activities were almost non-existent. Most educators had taught at least two online courses. 


\section{Simulation activities}

This cluster groups courses in which learning activities were based on reality simulation exercises aiming to prepare students to solve real problem situations. Conferencing was used for the planning, preparation and implementation of the exercises. Face-to-face and online were well balanced while online individual activities were again almost non-existent. Data collected showed that only educators applying networked teaching for the first or the second time proposed simulation-based activities.

\section{Theme development, text structuring and case study}

This cluster groups courses organized around themes, case studies, text production and discussion, readings, and other written activities that happened, mostly, within online conferences. Face-to-face and online as well as individual and collaborative activities were well balanced. Both first timers as well as more experienced educators structured their courses in this cluster type.

\section{Network-enhanced lecture}

This cluster groups courses in which, in addition to face-to-face lectures, educators published and provided links to materials. Networked discussions were organized to enhance and complete the activities and tasks presented in the face-to-face classroom, or to support discussions that were often lacking in traditional lecture halls. Most activities and tasks were exclusively individual although face-to-face and online components were relatively balanced. All educators were new having no previous online teaching experience.

\section{Network-enhanced seminar}

This cluster groups courses in which thematic seminars took place partially in the online conferences. Seminar preparation typically commenced face-to-face while development and closing were completed through online conferences. Face-to-face and online as well as individual and collaborative activities were balanced. Most educators were inexperienced and were integrating technology into their teaching for the first time.

\section{Networked-enhanced teaching practicum}

This cluster groups clinical experiences in which conferences were established for use by student teachers to support discussions related to learning needs and professional and practicum problems they encountered. Face-to-face and online as well as individual and collaborative activities were balanced. Most educators had already taught online, and when new, were mentored by experienced educators.

\section{Levels of collaboration}

We identified three general levels of collaboration in the clusters by combining the results of the interviews and the detailed analysis of a sampling of online conference transcripts (see Figure 1).

\section{Vague}

The most vague demonstration of collaboration was found in the most conventional cluster: lecture-based combined with networked activities. In this cluster, the concept of collaboration could be more closely identified with the definition of company (etymological meaning of the Latin word compania) denoting being with someone but not necessarily participating in a given activity / task, or working together. For example: a geography course in a mid-western Canadian university in which the professor taught his course face-to-face, and set up a VGroups conference only with the purpose of making available resources such as 
links to appropriate web sites, course notes, and messages with information concerning assignments and related tasks. The conference was never used for any kind of exchange with the students.

\section{Modest}

The most modest demonstration of collaboration was observed in the clusters in which people participated together in the same activity, but did not necessarily show indications of working or building knowledge together. These clusters were based on theme development, text structuring and case studies, teaching practica, and networked-enhanced seminars. Of the courses grouped into this cluster, collaborative and individual activities were balanced. In these clusters, the concept of collaboration could be more closely identified to the definition of cooperation (etymological meaning of the Latin word cooperatio) meaning acting together. We found a varying degree of collaboration across the clusters mentioned. For example: an education course in an Eastern American university in which students were invited to participate voluntarily in online discussions about pedagogical subjects related to a number of activities happening during face-toface encounters. Although students exchanged their viewpoints online, they were not requested to intentionally search for solutions to relevant problems.

\section{Strong}

The strongest demonstration of collaboration was observed in the clusters in which high levels of active learning were implemented: simulation activities and collaborative learning projects. The concept of collaboration developed in the networked-class dynamics was similar to the meaning of collaboration, (etymological meaning of the Latin word collaborare) denoting working together. For example: a business course in a French-speaking Eastern Canadian university in which the professor based the course on a problem-solving process. Students were given fictitious problematic business scenarios during face-to-face meetings that had to be solved through online discussions. The resulting conference contributions were complex argumentation processes in which points of view were confronted, reality checks were simulated, and understanding through knowledge building was achieved.

It is note-worthy that a relationship existed between levels of collaboration and educators' experience in a networked classroom. Both experienced and new educators organized cooperative and collaborative activities in a moderately balanced manner. Nonetheless, it was evident that educators without online experience organized activities that applied only minimal collaboration activities. 


\section{Individual Activities}

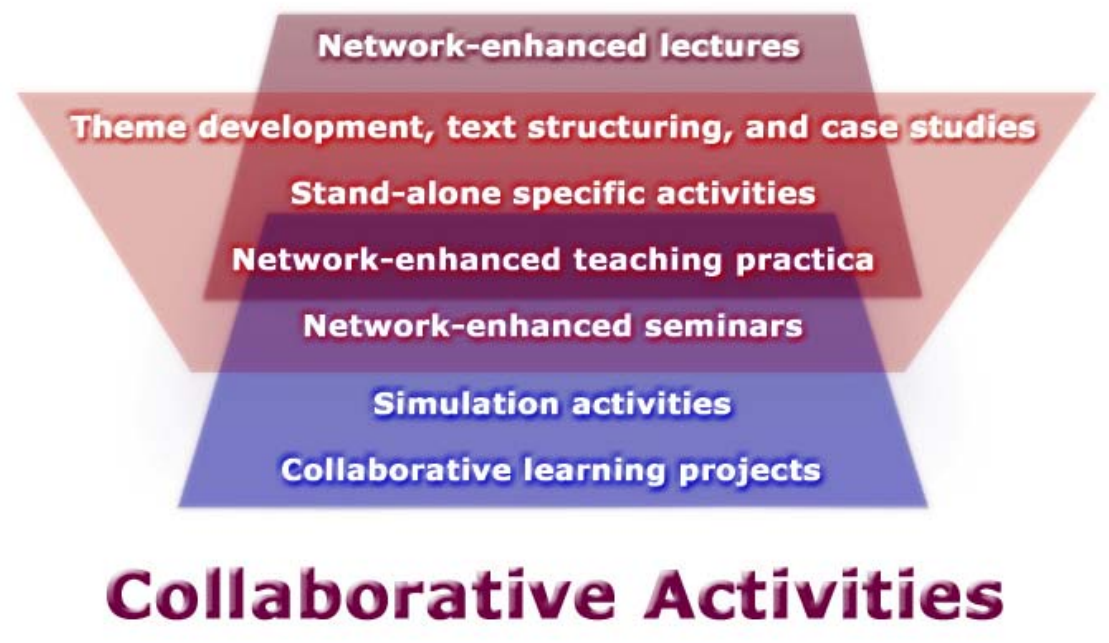

Figure 1 - Pedagogical-action clusters according to levels of collaboration.

These levels of collaboration also reflect the concepts or thoughts voiced by the interviewed educators as it relates to their definition of collaboration in educational settings. Their concepts about collaboration were neither intentionally applied nor pure in form, but were rather the unintended result of the manner in which they set up their courses. Few educators intentionally set up activities based on the belief that collaboration would enhance learning. Educators often combined activities that presumed involvement at different levels of collaboration. Consequently, the degree of collaboration was visible within the dynamics of interaction in the networked classrooms.

\section{THE NETWORKED CLASSROOM}

\section{A. A proposed model}

The findings of the mixed-mode courses studied point to an understanding of the networked classroom in the context of post-secondary educational institutions. This emerging trend offers new ways of addressing the place for learning technologies in education. Results stress the importance of the central role of social actors (e.g. teacher, learner) in pedagogical actions, both shaping and being shaped by cultural processes enabled by the integration of information and communication technologies.

The notion of the networked classroom warrants clarification as the term is typically applied according to pedagogical and technological contexts that are not always consistent. For example: does a totally online course that does not apply communication technologies (such as synchronous or asynchronous conferencing) constitute a networked classroom? Factors such as the support provided and constraints imposed by educational institutions, technologies used for learning activities, experience of educators and students using computers and networks, course constraints, disciplines, cultures, etc., need to be considered. We argue, however, that the true definition of networked classroom lies within the level of collaboration that results from the integration of face-to-face and online socio-cognitive dynamics. In other words, social interaction is enhanced by the integration of conferencing. Networked classrooms can thus be defined as socio-cognitive mixed-mode learning spaces enabled by technology. 
This definition, therefore, forms the basis for a proposed model representing an integrative vision for teaching and learning in the networked classroom. This model is also based upon the notion that interaction between the knowing subject and the object of knowledge, as well as the interactions between subjects, mold each other (co-constitutionality). This model supports the importance of assisting educators in designing collaborative mixed-mode environments by including ALN asynchronous learning networks that enhance both their teaching practices and student learning.

The proposed model assumes that the subjects' actions cannot be understood as pure or simple "effects." The cognitive structures resulting from organic brain processes are necessary but not sufficient to explain the emergence of actions in a dynamic situation such as pedagogical communication. It is through the creative paths of language that cognition unfolds because human actions are not mechanisms that can be isolated from the living history of the knowing subject [26]. Interacting with the world, including online interaction, implies a dynamic symbolic flexibility that has a logical dimension (neural systems) as well as a meaning dimension (symbolic historical contents of the individual's life that are "printed in" neural systems). The neuronal systems that result from the interaction between the subject and the world correspond to "knowledge construction" [20]. The resulting symbolic configurations triggered by these systems directly correspond to "knowledge building," the intentional process [24] of the subjects in their attempts to "make sense" of given content (understood here as interdependence of intentionalities [25]), to solve both well- and ill-defined problems, making use of procedures being taught or already learned, and the several semiotic levels of the meanings built in a lifetime through language [26]. Both dimensions are indivisible components of the human's knowledge acquisition process.

The concept of cognitive structures implies that the subjects' actions are at the center of the knowing process, not the object of knowledge. Consequently, the integration of technology occurs in such a way that focuses on the fact that the knowing processes enhance the subjects' actions. Knowledge construction together with knowledge building enables and is enabled by the use of technology. Take, for example, the simple use of a pen. It responds to man's intentional expression needs of going through the creative reproductive paths of the writing process. Adopting networked technologies can be viewed as the opportunity to enhance our intentional needs for expressing and negotiating meanings with others. The resulting shared object of knowledge then shapes the subject's symbolic behavior in a continued and constitutive process.

Applying this concept to the networked classroom provides for the formulation of a notion for networkmediated pedagogical action, or co-constitutive communicative interaction that integrates conferencing technology. This notion bases intentional pedagogical actions, that is, the establishment of goals, activities, tasks, organization, and attribution of roles and rules to be consensually agreed upon by the learning partners. Our analysis suggests that networked classrooms allow the emergence of learning actions that can lead to collaborative knowledge construction and building. 


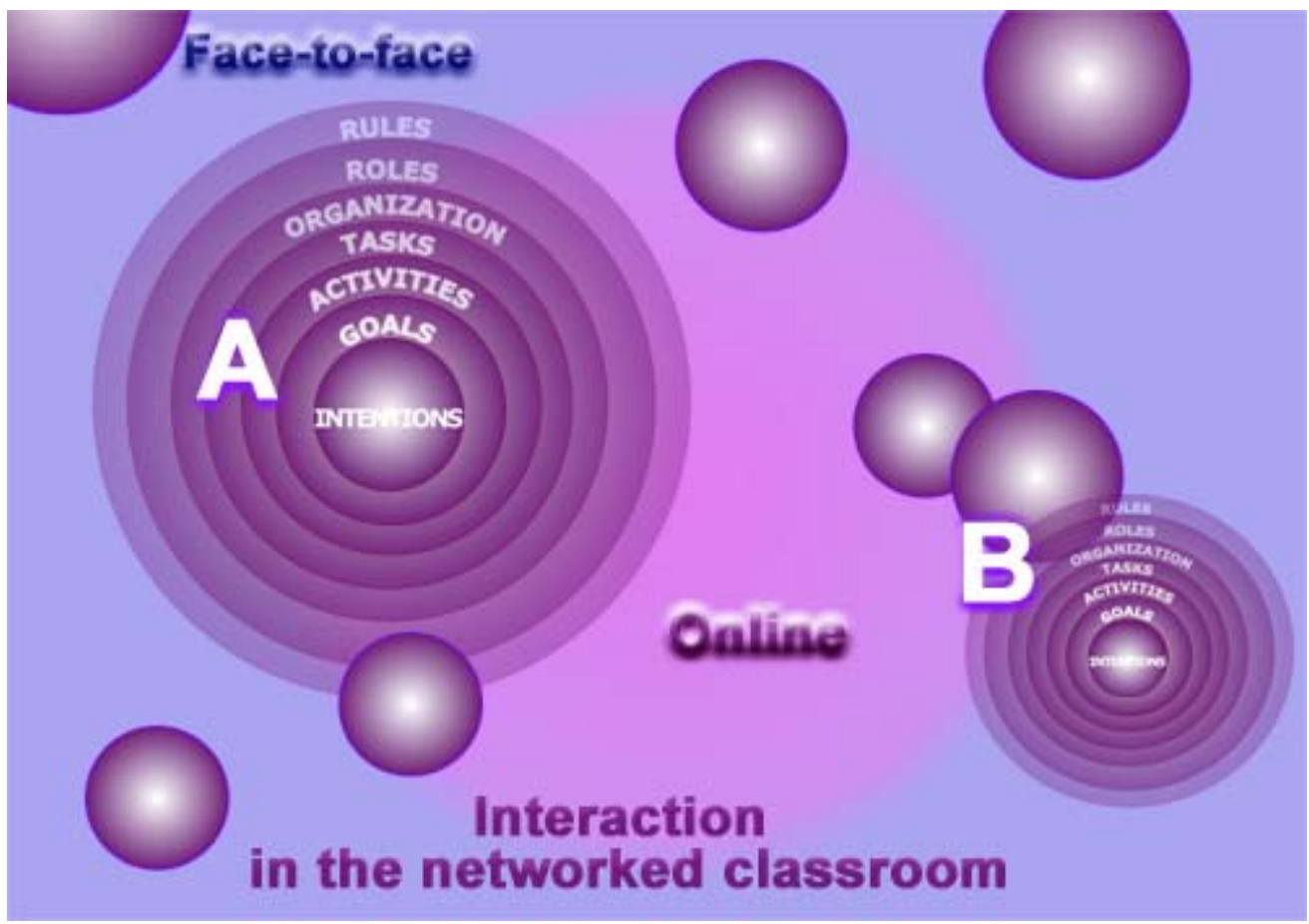

Figure 2 - The networked classroom.

Sphere A represents the educator's pedagogical action in the mixed-mode environment (face-to-face is blue, and online is purple). Sphere B represents the different responses from students to both the educator and one another.

The complementary teaching and learning dimensions of the pedagogical action manifests itself in the networked classroom: an integrated socio-cultural space of sharing (face-to-face and online) enabled by pedagogy and technology. It is, however, the level of collaboration triggered by the pedagogical action that defines a networked classroom. The networked classroom is shaped by and through pedagogical actions and their distinct paths, and where the educator intervenes to promote collaborative knowledge sharing. The level of collaboration propitiated by the actions of the educators in a networked classroom is elevated through their ability to create, implement, and nurture an effective learning environment. In the networked classroom, students have the opportunity to leverage interests through to other students.

Different types of networked classrooms are presented below. The pedagogical actions that educators initiate by integrating online conferences into the traditional classroom affect the learning paths of students. The closer that the students are positioned in a given mixed-mode setting, the stronger the level of collaboration is likely to be. This model could essentially be used to indicate whether a given pedagogical action will enable a greater or lesser degree of collaboration, and whether it will provide enriched or inferior social interaction.

\section{B. Types of networked classrooms}

Our data analysis led to a three-level classification of networked classrooms: the Net-showroom, the Netmeeting room, and the Net-workshop. This classification captures the way in which the majority of educators set up their learning space in order to achieve their pedagogical goals, and also corresponds to the levels of collaboration identified (vague, modest and strong). 
The Net-showroom is a networked classroom in which online learning environments are spaces for publishing and viewing materials. Of the courses analyzed, pedagogical action in this classification satisfied only a primary level of knowledge sharing. In instances where some interaction occurred through conferencing, most of the activities and tasks were exclusively publishing and viewing related. It is therefore inherent that in this type of networked classrooms, a collaborative knowledge-building environment is not being provided to students.

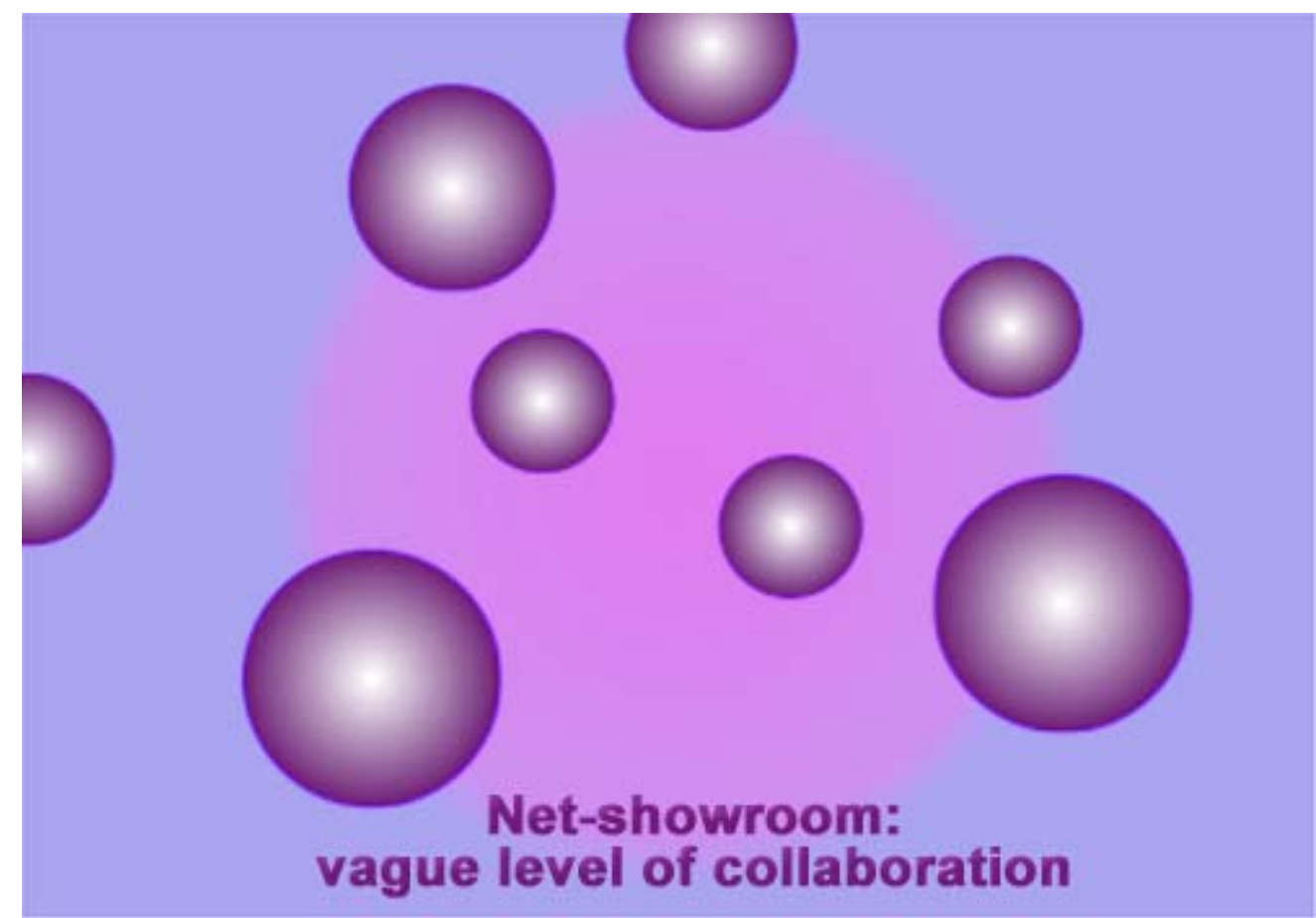

Figure 3 - The net-showroom: vague collaboration.

The spheres represent classroom members interacting episodically online (purple) and face-to-face (blue) in a group that is not very engaged in common activities.

The Net-meeting room is a type of networked classroom in which virtual learning environments are used as cooperative spaces for highly structured interactions. Networked classrooms of this type embody pedagogical actions that trigger knowledge exchange through conferencing yet without a strong commitment to knowledge sharing and negotiation of meanings. 


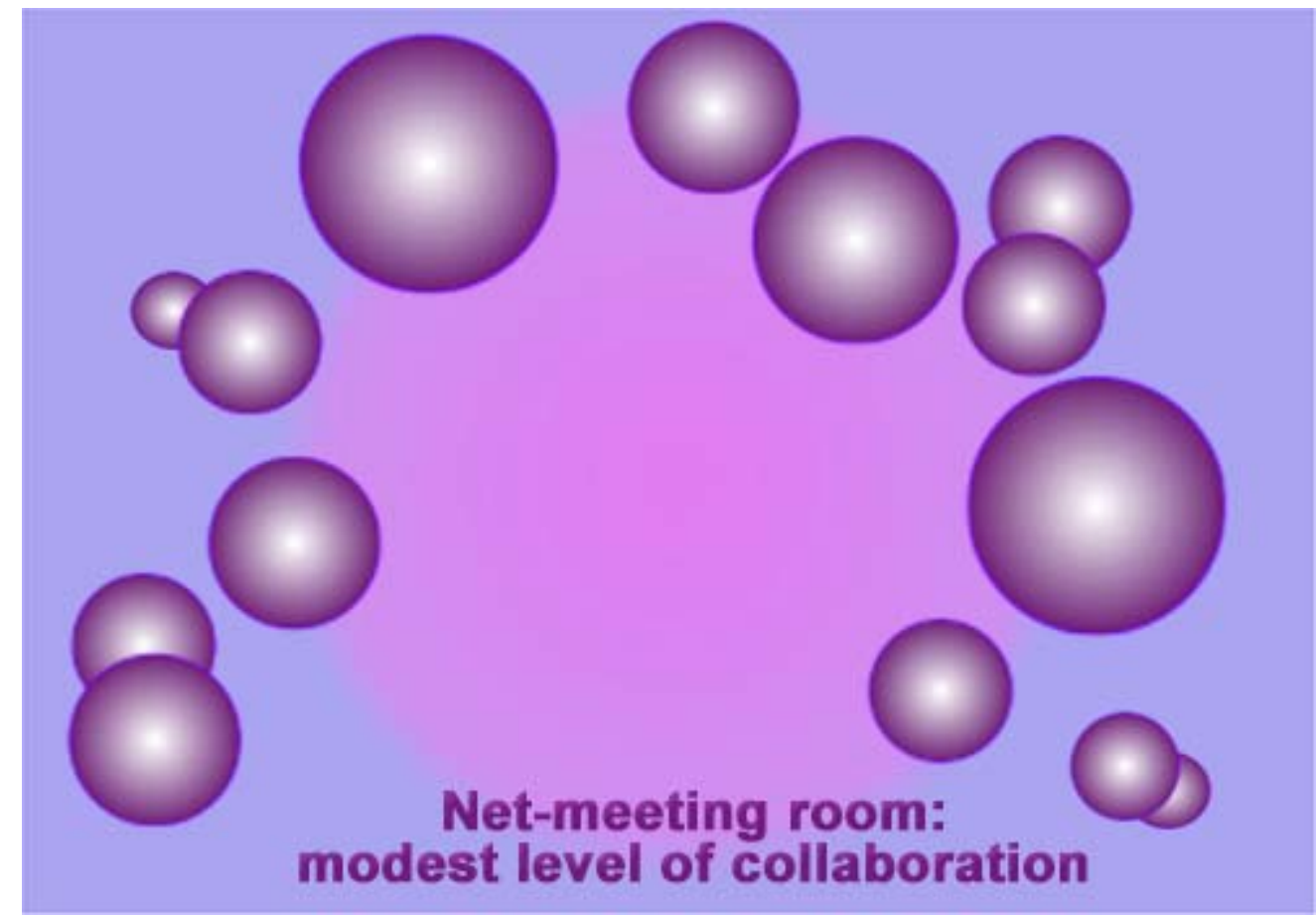

Figure 4 - The Net-meeting room: modest collaboration.

The spheres represent students' integration of online (purple) and face-to-face (blue) components more consistently. This type of networked classrooms engages in balanced online and face-to-face activities.

The Net-workshop is the type of networked classroom that uses collaborative virtual spaces for social learning and knowledge building. In this classification, the online conferences are at the core of most of the face-to-face and virtual activities.

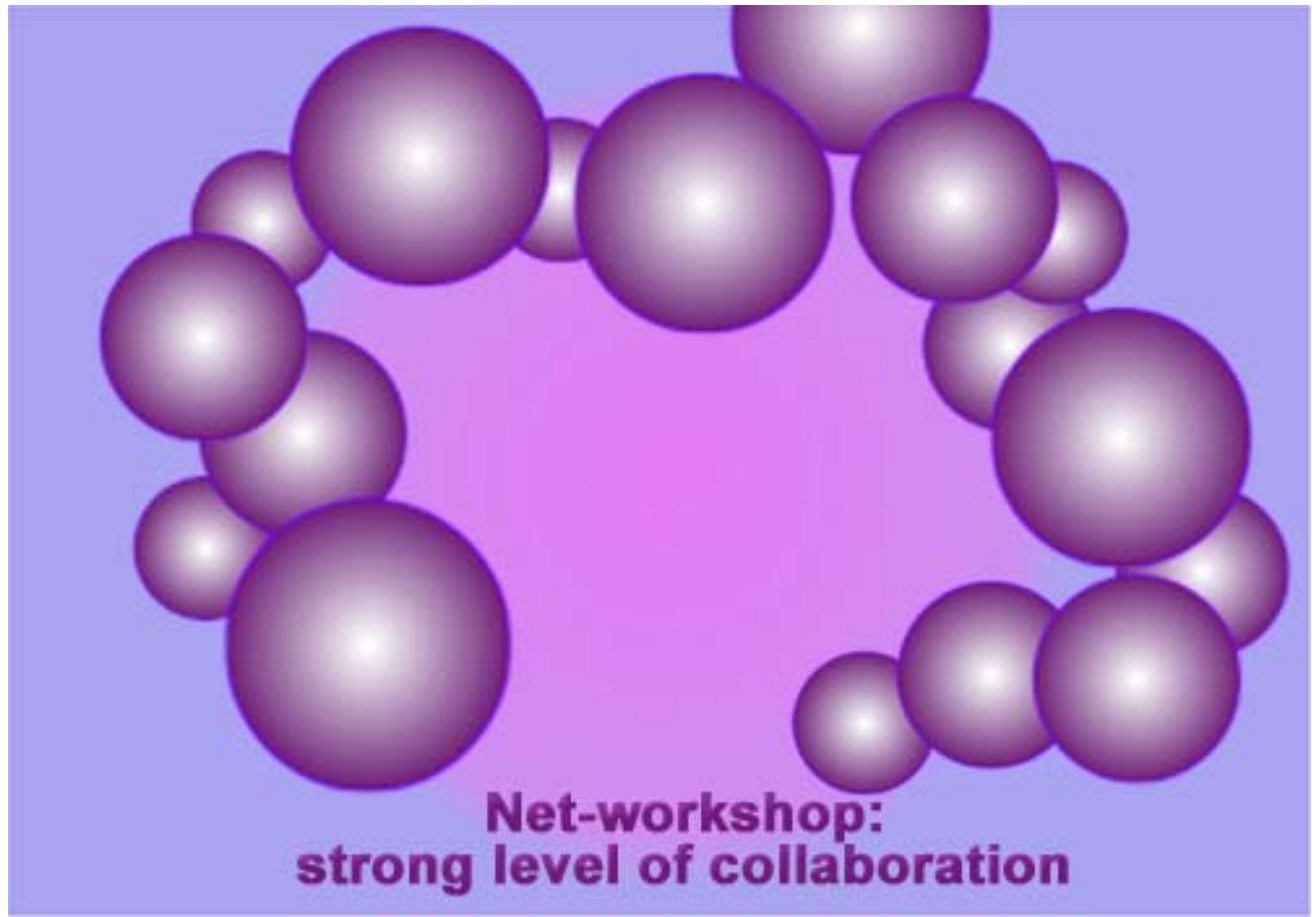

Figure 5 - The Net-workshop: strong collaboration. 
The spheres represent students engaged in intentional common activities. The group interacts in both online (purple) and face-to-face (blue) activities through the conferencing system, and its thought sharing possibilities are at its center.

The purpose of our study is to help support educators as they design and reflect upon the most appropriate pedagogical actions to be considered and adopted for the networked classroom. It is the opinion of the authors that while none of the above types of networked classrooms reached through this study should be deemed as superior, the Net-workshop is the one in which educators can take full advantage of networked technologies to enhance and advance online teaching and learning.

\section{CONCLUSION}

By presenting the data collected, our study highlights a move from peripheral-collaborative to basiccollaborative activities occurring in the classroom. The studied instructional experiences suggest that educators are integrating conferencing technology into their teaching in creative and dynamic ways. Indeed, results point to a re-discovery of the art of teaching with the support of new technologies. The variety of ways in which online and face-to-face interactions were combined is tangible evidence of the rich potential that computer-supported classroom interaction holds.

The study shows that even the most individualized activity presents a minimal level of collaboration. The findings highlight the pedagogical opportunities that technology offers to education and the profound changes that networked classrooms may bring to the very nature of the teaching and learning experience. This study also demonstrates the correlation between the collaborative pedagogical action cluster chosen by educators and their online teaching experiences. Based on this correlation, the assumption is therefore taken that the more online experience educators possess, the less they focus on individual processes and benefit from the advantages and collaborative possibilities that new learning technologies bring.

It is worth noting that the degree of collaboration depends largely on the ability of educators to respond to the requirements of the newborn knowledge society in the process of intertwining practice and pedagogical ideas through networking [5] [12] [1] [6]. The integration of digital networks is particularly visible in the use of conferencing: exchanges are registered in the system forming a database of the knowledge built [24], the Boolean structure of the conferencing trees allow a minimal structuring of knowledge and intellectual exchange based on specific subjects of discussion although it needs further development [11], there is a renewal of the social learning practices [18] [3] [7], and research discussions [8] and recent studies [10] highlight how writing collaboratively may enhance the quality of learning in the networked classroom.

Such research results, however, are not always evident to those working within the confines of institutional walls. During the interview process of this study, educators stressed that they wanted to learn how to moderate online conferences, and to know what other educators were doing when preparing and implementing mixed-mode courses. They showed interest in studies summarizing mixed-mode experiences in post-secondary institutions that could provide guidance, new ideas, and an understanding of this emerging teaching mode. Research into the implementation of technology in the context of elementary, secondary schools and institutions of higher education also identified these interests and needs [17].

This study strongly suggests that the pedagogical possibilities of conferencing are immense, as shown by the variety of pedagogical-action clusters identified. Most activities and tasks were carried out either in or through electronic conferencing. Moreover, we suggest that conferencing systems are being increasingly seen as communication systems able to enhance collaborative knowledge sharing. The varying degree of 
collaboration and types of networked classrooms identified serve to guide post-secondary educators in the planning of mixed-mode courses.

Finally, this study shows that educators are learning how to integrate networked activities through applying and transferring their face-to-face expertise into the online environment. The findings and model identified present a first step for considering the dynamics of online course design. They can be applied in a number of educational mixed-mode contexts that include ALN - asynchronous learning networks. The transformation processes that networking and technology offer to post-secondary institutions, and the need of sharing practical-pedagogical knowledge to better incorporate technology in education are critical not only today but for the future as networked learning becomes an integral part of the evolution of post-secondary education and social practice.

\section{ACKNOWLEDGEMENTS}

Funding for this study was received from the University of Montréal and Canada's TeleLearning Network of Centres of Excellence. The authors wish to thank the professors who collaborated with this research, Dr. Alain Breuleux (McGill University) for making this study possible, Dr. Jean Benoit (Université Laval), and to Valerie Gafka (TeleLearning NCE) for editorial contributions.

\section{REFERENCES}

1. Becker, H., \& Riel, Teacher professionalism, school work culture and the emergence of constructivist-compatible pedagogies, Proceedings of AERA Conference, Montréal, 1999. http://www.crito.uci.edu/tlc/findings/special report2/

2. Bellamy, R. K. E., Designing educational technology: Computer-mediated change. In B. A. Nardi (Ed.), Context and Consciousness: Activity theory and human-computer interaction, The MIT Press, Cambridge, MA, 123-146, 1996.

3. Benoit, J., De la communauté d'apprentissage à la communauté de pratique en ligne : une réflexion prospective et la construction d'un modèle de design polyvalent pour des fins d'apprentissage et de travail [From the online learning community to the online community of practice: a prospective reflection and a temptative model of polivalent design for learning and work purposes] Master thesis, Université Laval, Department of Teaching and Learning Studies, 1999.

4. Bereiter, C. \& Scardamalia, M., Rethinking learning. In Olson, D. R. and Torrance, N. (Eds.), The handbook of education and human development: New models of learning, teaching, and schooling, Basil Blackwell, Cambridge, MA, in press.

5. Bracewell, R., Breuleux, A., Benoit, J., Abdous, M., \& Laferrière, T., The emerging contribution of online resources and tools to classroom learning and teaching. Ottawa: Industry Canada, SchoolNet, 1998. http://www.tact.fse.ulaval.ca/ang/html/review98.html

6. Bracewell, R. J., Breuleux, A., \& Le Maistre, C., The role of the teacher in opening worlds of learning with technology. In B. M. Shore, M. W. Aulls, M. A. B. Delcourt, \& F. G. Rejskind (Eds.), Inquiry: Where ideas come from and where they lead, Lawrence Erlbaum Associates, Mahwah, NJ, 2000. http://telelearning.mcgill.ca/Publications/BracewellEtAl.pdf

7. Brown, J. S., \& Duguid, P., The social life of information, Boston, Harvard Business School Press. MA, 2000.

8. Bruer, J.T., Schools for thought: A science of learning in the classroom, MIT Press, Cambridge, MA, 1994.

9. Campos, M. N., Competition, lies and dissimulation: lessons from an online learning clash, Interpersonal Computing and Technology Journal, in press. 
10. Campos, M. N., The hypermedia conversation: reflecting upon, building and communicating illdefined arguments, Interactive Multimedia Electronic Journal of Computer-Enhanced Learning, 2, 2, 2000. http://imej.wfu.edu/articles/2000/2/04/index.asp

11. Campos, M. N., Conditional reasoning: A key to assessing computer-based knowledge-building communication processes, Journal of Universal Computer Science, 4, 4, 404-428, 1998. http://www.iicm.edu/jucs 4 4/conditional reasoning a key/paper.htm

12. Campos, M. N., \& Harasim, L. Virtual-U: results and challenges of unique field trials, The Technology Source, 6, 1999. http://horizon.unc.edu/TS/vu/1999-07.asp

13. Cole, M., \& Engestrom, Y., A cultural-historical approach to distributed cognition. In G. Salomon (Ed.), Distributed cognitions: Psychological and educational considerations, University Press, Cambridge, 1-47,1993.

14. Harasim, L. M., Online education: an environment for collaboration and intellectual amplification. In Harasim, L. M. (Ed.), Online education: perspectives on a new environment, Praeger, New York, 39-66, 1990.

15. Harasim, L., Hiltz, S. R., Teles, L, \& Turoff, M., Learning networks: A field guide to teaching and learning online, MIT Press, Cambridge, MA, 1995.

16. Harasim, L., A framework for online learning: the Virtual-U, Computer, 32 (9), 44-49, 1999. http://computer.org/computer/co1999/r9044abs.htm

17. Laferrière, T., Breuleux, A., Fitzsimons, R., \& Baker, P., In-service teachers professional development models in the use of information and communication technologies, Report to the SchoolNet National Advisory Board, 1999. http://www.tact.fse.ulaval.ca/ang/html/pdmodels.html

18. Laferrière, T., Breuleux, A. \& Campos, M., L'évolution des métiers et des formations dans les nouvelles méthodes de production des connaissances. L'apprentissage en réseau, une réalité pédagogique à définir, Proceedings of the Colloquium Initi@tives99: vers un enseignement égalitaire [Initi@tives99: Towards an egalitarian education], News Brunswick, 27-30 August, 1999. http://www.aupelf-uref.org/initiatives/colloque/

19. Palloff, R. M., \& Pratt, K., Building learning communities in cyberspace:Effective Strategies for the Online Classroom, Jossey-Bass Publishers, San Francisco, 1999.

20. Piaget, J. Biologie et connaissance. essai sur les relations entre les régulations organiques et les processus cognitifs [Biology and Knowledge: Essay on the Relationship between Organic Regulations and Cognitive Processes], Delachaux et Niestlé, Nêuchatel-Paris, 1992.

21. Piaget, J., La naissance de l'intelligence chez l'enfant [The origin of intelligence in the child], Delachaux et Niestlé, Nêuchatel-Paris, 1977. (Original work published 1947)

22. Piaget, J.,La construction du réel chez l'enfant [The construction of reality in the child], Delachaux et Niestlé, Nêuchatel-Paris, 1977b. (Original work published 1936)

23. Piaget, J.,La formation du symbole chez l'enfant : imitation, jeu et rêve, image et répresentation [Plays, dreams and imitation in childhood], Delachaux et Niestlé, Nêuchatel-Paris, 1976. (Original work published 1947)

24. Scardamalia, M. \& Bereiter, C., Computer support for knowledge-building communities, The Journal of the Learning Sciences, 3 (3), 265-283, 1994.

25. Varela, F. J., The specious present: a neurophenomenology of time consciousness. In: Petitot, J, Faveral, F.J., Pachoud, B., and Roy, J.-M., Naturalizing phenomenology. Issues in contemporary phenomenology and cognitive science, Stanford University Press, Stanford, 266-314, 1999.

26. Varela, F. J., Invitation aux sciences cognitives [Invitation to the cognitive sciences], Éditions du Seuil, Paris, 1996. (Original work published 1988)

27. Vygotsky, L. S., The collected works of L.S. Vygotsky (edited by Robert W. Rieber and Aaron S. Carton; prologue by Jerome S. Bruner), Vol. 1, Problems of general psychology,Plenum Press, New York, 1998.

28. Wenger, E., Communities of practice: learning, meaning and identity, Cambridge University Press, Cambridge, 1998. 


\section{ABOUT THE AUTHORS}

Milton Campos is Assistant Professor at the Department of Communication of the Université de Montréal. His post-doctoral research on networked communication as applied to education was carried out at Simon Fraser University, in collaboration with the TeleLearning - Network of Centres of Excellence. His present research interests are: socio-cognitive theories of hypermedia and multimedia communication; discourse analysis of communicative interaction in networked communities (learning communities, communities of practice and communities of interest), and software development of asynchronous multimedia conferencing systems.

Thérèse Laferrière is Professor at the Department of Teaching and Learning Studies of the Université Laval, former Dean of Education. She is currently the leader of the research theme "Educating the Educators" within the TeleLearning Network of Centres of Excellence. The NCE Program is administered by the three Canadian granting councils: The Natural Sciences and Engineering Research Council (NSERC), the Social Sciences and Humanities Research Council (SSHRC), and the Medical Research Council (MRC), in collaboration with Industry Canada. Her research activities focus on teacher-student(s) interactions and peer interactions in elementary, secondary, and post-secondary networked classrooms.

Linda Harasim is Professor at the School of Communications of Simon Fraser University, and Telelearning - Network of Centres of Excellence CEO (1995-2001). She has produced three widely recognized books on online learning: Online Education: Perspectives on a New Environment (1990), Global Networks: Computers and International Communications (1995), and Learning Networks: A Field Guide to Teaching and Learning Online co-authored with Starr Roxanne Hiltz, Lucio Teles, and Murrary Turoff (1995). Her research focus on the development of a leading online learning environment: Virtual-U.

\footnotetext{
${ }^{1}$ The first networking experiences go back to the $60 \mathrm{~s}$ in the United States; the early availability of e-mail in the mid-70s provided some enhancement on the level of exchange; computer-supported conferencing was incorporated to instruction in the 80s [14]; but only in the 90s did networks become visible as web-based communication.

${ }^{2}$ Virtual-U is an online learning environment conceptualized to support collaborative learning and knowledge building among participants. Features include course management, instructor-student and student-student communication, teaching and learning resources, and also other tools (See http://virtual-u.cs.sfu.ca/vuweb/VUenglish/). The software was developed by the Virtual-U Research Project as part of Canada's TeleLearning Network of Centres of Excellence (See http://www.telelearn.ca). Virtual-U is being further developed in collaboration with the Simon Fraser University spin-off company VLEI - Virtual Learning Environments Inc. (See http://www.vlei.com).

${ }^{3}$ We applied the meaning implication technique for the analysis of the online collaborative discourse of a sample of the course data. This technique identifies configurations of meanings in the threaded conversation through meaning implications, aiming to understand how learners build upon the contributions of others. Meaning implications are conditional statements that function as premises of arguments. In other words, we look for the chains of conditional statements linking different messages through common meanings, and then try to identify the main themes (configurations of meanings) of the online communication exchange and knowledge building (see [9], [10], and [11]).

${ }^{4}$ In addition to VGroups, the conferencing system, Virtual-U, has a number of tools for supporting online teaching and learning like: a course management tool to make available syllabus and other resources to the students, a gradebook to allow the structuring of evaluation, a workspace for personal organization, among others.

${ }^{5}$ In some few courses professors used conferencing as a publishing tool for informing students about deadline for assignments and other course related activities, and for providing links to interesting websites (see below).

${ }^{6}$ Collaborative knowledge building is a conscious process of inquiry and continuous intentional adaptation [23] [4] in which the learners engage collectively to generate, link and structure ideas [13] to acquire expertise in a given domain [8], with the goal of solving ill-defined problems around which online activities like conference discussions were built [9] [10].
} 